\title{
Signs of beta-cell autoimmunity and HLA-defined diabetes susceptibility in the Finnish population: the sib cohort from the Type 1 Diabetes Prediction and Prevention Study
}

\author{
M. Kukko², 6, T. Kimpimäki², 6, A. Kupila ${ }^{3,6}$, S. Korhonen ${ }^{4,}$, , P. Kulmala ${ }^{4,6}$, K. Savola ${ }^{4,}$, , T. Simell ${ }^{3,6}$, \\ P. Keskinen ${ }^{3,}$, J. Ilonen ${ }^{5,}$, O. Simell3, 6, M. Knip ${ }^{1,2,6}$ \\ ${ }^{1}$ Hospital for Children and Adolescents, University of Helsinki, HUCH, Helsinki, Finland \\ ${ }^{2}$ Medical School, University of Tampere, and Department of Paediatrics, Tampere University Hospital, Tampere, Finland \\ ${ }^{3}$ Department of Paediatrics, University of Turku, Turku, Finland \\ ${ }^{4}$ Department of Paediatrics, University of Oulu, Oulu, Finland \\ ${ }^{5}$ Department of Virology, University of Turku, Turku, Finland \\ ${ }^{6}$ JDRF Center for Diabetes Prevention in Finland
}

\begin{abstract}
Aims/hypothesis. To assess the role of HLA-defined genetic diabetes susceptibility in the appearance of signs of beta-cell autoimmunity in a series of children derived from the general population.

Methods. Tests for five HLA DQB1 alleles and four diabetes-associated autoantibodies were carried out on 1,584 older sibs of infants with an increased HLA-defined genetic risk of Type 1 diabetes. The $D Q B 1$ genotypes were classified into those conferring high $(* 02 / 0302)$, moderate $(* 0302 / x$; where $\mathrm{x}$ indicates $* 0302$ or a non-defined allele), low $(* 0301 / 0302$, $* 02 / 0301, * 02 / x, * 0302 / 0602, * 0302 / 0603$; where $\mathrm{x}$ indicates $* 02$ or a non-defined allele) or decreased risk (other genotypes).

Results. Both islet cell antibodies (ICA) and GAD65 antibodies (GADA) were more frequent among the sibs with the high-risk genotype than among those
\end{abstract}

with a low or decreased risk. Insulin autoantibodies and IA-2 antibodies (IA-2A) were more prevalent in the high-risk than low-risk sibs. Sibs with moderaterisk genotypes tested positive for ICA, GADA and IA-2A more often than sibs with genotypes conferring decreased risk. Autoantibody titres were also dependent on the genetic risk with high risk sibs having the highest values. Sibs carrying high-risk or moderaterisk genotypes tested positive for multiple antibodies $(\geq 2)$ more often than did the sibs with low or decreased genetic risk.

Conclusions/interpretation. The data show that HLAdefined susceptibility to Type 1 diabetes has an effect on both the quality and quantity of humoral beta-cell autoimmunity in unaffected children derived from the general population. [Diabetologia (2003) 46:65-70]

Keywords Type 1 diabetes, HLA-DQB1, Autoantibody, Finland, General population, Risk group.
The incidence of Type 1 diabetes, which is one of the most common chronic disorders in children and adolescents [1], has gradually increased since World War II in most Western countries [2, 3], the highest being in Finland [4, 5, 6, 7, 8]. Clinical disease represents end-stage insulitis which is a consequence of progres-

Received: 11 April 2002 / Revised: 10 July 2002

Published online: 18 December 2002

(C) Springer-Verlag 2002

Corresponding author: M. Knip, Hospital for Children and Adolescents, University of Helsinki, P.O. Box 281, 00029 HUCH, Helsinki, Finland, E-mail: mikael.knip@hus.fi sive destruction of beta cells in the islets of Langerhans after an asymptomatic period of variable duration $[9,10]$. During this asymptomatic phase, autoantibodies associated with Type 1 diabetes can be detected in subjects who are still normoglycaemic. At the moment, four antibodies are used as markers of betacell autoimmunity: islet cell antibodies (ICA), insulin autoantibodies (IAA), antibodies to the $65 \mathrm{kD}$ isoform of glutamic acid decarboxylase (GADA) and antibodies to the tyrosine phosphatase-related IA-2 molecule (IA-2A).

Type 1 diabetes is a multifactorial disease with a strong genetic predisposition. The most important genes contributing to disease susceptibility are located 
in the HLA-DQ locus on the short arm of chromosome 6, 6p21 [11, 12]. Mathematical models based on twin and family studies and HLA association analyses have indicated that 30 to $60 \%$ of the genetic component of Type 1 diabetes can be accounted for by associations with genes of the HLA complex [13]. HLA-DQB1 alleles also confer resistance to Type 1 diabetes, the strongest protective HLA class II allele being DQB1*0602. A number of DQB1*0602-positive relatives of patients with Type 1 diabetes test positive for ICA but it is extremely rare for any of these subjects to progress to clinical diabetes [14]. There are indications that isolated ICA positivity is not related to the genetic risk of Type 1 diabetes, while positivity for two or more antibodies, which is associated with an increased risk of Type 1 diabetes in first-degree relatives $[15,16,17]$, is closely linked to increased genetic disease susceptibility. Beta-cell autoimmunity could be induced in any subject, irrespective of the genetic risk, but HLA-conferred resistance will protect most subjects from progressing to Type 1 diabetes [10]. DQB1*0602-defined protection seems to be dominant over susceptibility conferred by the DQB1 alleles $* 0302$ and $* 0201[14,18]$.

Our study was aimed at assessing the role of HLAdefined genetic disease susceptibility and protection in the appearance of signs of beta-cell autoimmunity in a series of children derived from the general population.

\section{Subjects and methods}

Subjects. The cohort comprised 1584 older sibs (783 males; $49.4 \%$ ) of infants taking part in the Finnish Type 1 Diabetes Prediction and Prevention Project (DIPP), which is aimed at identifying newborn infants who have an increased genetic risk of developing Type 1 diabetes (phase I), recognising at an early stage the appearance of markers of autoimmunity known to precede clinical Type 1 diabetes in those with genetic susceptibility (phase II) and delaying the onset of clinical disease in those at genetic risk with signs of beta-cell specific autoimmunity (phase III) [19]. In the DIPP study families with an infant carrying increased genetic susceptibility to Type 1 diabetes (HLA DQB1*02/0302 or 0302/ $; x \neq * 0301, * 0602, * 0603$ ) were invited for observation and immunological surveillance for the emergence of diabetes-associated autoantibodies and development of Type 1 diabetes. The unaffected older sibs of the genetically susceptible infants were also invited for genetic and autoantibody screening, and 1584 such sibs with a mean age of 6.2 years (SD 3.5, range 1.2-24.1 years) had taken part in the study by the beginning of June 1999. Blood samples were obtained at an outpatient visit for $D Q B 1$ genotyping and testing for ICA, IAA, GADA and IA-2A. Of the sibs $38(2.4 \%)$ had at least one first-degree relative (10 mothers, 19 fathers, 7 sibs and 2 families with both an affected mother and sibling) with Type 1 diabetes. The DIPP study protocol was approved by the ethical committees of the three participating hospitals (Oulu, Tampere and Turku University Hospitals).

Genetic screening. HLA-DQB1 typing was carried out by a method based on time-resolved fluorescence [20]. We used five sequence-specific oligonucleotide probes to identify the following $D Q B 1$ alleles known to be associated with either susceptibility to or protection against Type 1 diabetes in the Finnish population: $D Q B 1 * 0302, \quad D Q B 1 * 02, \quad D Q B 1 * 0602$, $D Q B 1 * 0603$ and $D Q B 1 * 0301$ [21]. The sibs were classified into four risk groups based on their $H L A D Q B 1$ genotype using a simplified classification: high risk $(D Q B 1 * 02 / 0302)$, moderate risk $(D Q B 1 * 0302 / x$; where $\mathrm{x}$ indicates $* 0302$ or a non-defined allele), low risk $(D Q B 1 * 0301 / 0302, D Q B 1 * 02 / 0301$, $D Q B 1 * 02 / x, \quad D Q B 1 * 0302 / 0602, \quad D Q B 1 * 0302 / 0603$; where $\mathrm{x}$ indicates $* 02$ or a non-defined allele) and decreased risk (protection) $(D Q B 1 * x / x, \quad D Q B 1 * 0301 / x, \quad D Q B 1 * 02 / 0602$, $D Q B 1 * 02 / 0603, D Q B 1 * 0602 / x, D Q B 1 * 0603 / x$; where $\mathrm{x}$ indicates a non-defined allele) [21].

Antibody analyses. All assays of diabetes-associated autoantibodies were done in the Research Laboratory of the Department of Paediatrics, University of Oulu. ICA were quantified by a standard immunofluorescence method on sections of frozen human pancreas from a blood group $\mathrm{O}$ donor [22], and detected with sheep fluorescein-conjugated anti-human IgG (Sigma, St.Louis, Mo., USA). The end-point dilution titres of the ICA-positive samples were recorded and the results expressed in Juvenile Diabetes Foundation (JDF) units. The detection limit was 2.5 JDF units. Our research laboratory participated in the international workshops on standardisation of the ICA assay, in which its sensitivity was $100 \%$ and specificity $98 \%$ in the most recent round. All samples that were initially positive for ICA were re-tested for confirmation.

Serum titres of IAA were quantified with a microassay modified from that described by another study [23]. Antibodyantigen complexes were precipitated with protein A Sepharose (Pharmacia Biotech, Uppsala, Sweden) after incubation of the serum samples with mono-125I-TyrA14-human insulin (Amersham, Little Chalfont, Bucks, UK) for $72 \mathrm{~h}$ with or without an excess of unlabelled insulin. The IAA values representing specific binding were expressed in relative units (RU) based on a standard curve run on each plate using the MultiCalc software program (PerkinElmer Life Sciences Wallac, Turku, Finland). A subject was considered positive for IAA when specific binding exceeded 1.55 RU (99th centile in 371 non-diabetic Finnish subjects). The disease sensitivity of our microassay was $35 \%$ and its specificity $100 \%$ based on 140 samples derived from the 1995 Multiple Autoantibody Workshop [24].

GADA were measured with a radiobinding assay as previously described [25]. The results were expressed in relative units (RU) based on a standard curve constructed from the dilution of a pool of highly positive samples with a negative sample. The cut-off limit for antibody positivity was set at the 99th centile for 373 non-diabetic Finnish children and adolescents, i.e. 5.36 RU. The sensitivity of the GADA assay was $69 \%$ and its specificity $100 \%$, based on 140 samples included in the 1995 Multiple Autoantibody Workshop [24]. IA-2A were quantified with a radiobinding assay [26], and antibody titres were expressed in RU based on a standard curve, as for GADA. The limit for IA-2A positivity was $0.43 \mathrm{RU}$, which represents the 99th centile in 374 healthy Finnish children and adolescents. The sensitivity of this assay was $62 \%$ and its specificity $97 \%$, based on 140 samples included in the 1995 Multiple Autoantibody Workshop [24]. All samples with IAA, GADA or IA-2A values between the 95th and 99.5th centiles were reanalysed to confirm their status.

Statistical analyses. The distribution of autoantibodies between risk groups was evaluated by cross-tabulation and Chi-Square statistics with Yates correction, unless any expected value was less than five, when Fisher's exact test was used. The Student's $t$ test was used to assess age differences. Kruskal-Wallis non- 
parametric analysis of variances and the Mann-Whitney U-test were used to compare antibody titres between the risk groups. A two-tailed $p$ value of 0.05 or less was considered statistically significant.

\section{Results}

Out of the 1584 sibs (from 985 families) studied, 171 $(10.8 \%)$ carried the high-risk genotype, $516(32.6 \%)$ moderate-risk genotypes, 422 (26.6\%) low-risk genotypes and $475(30.0 \%)$ genotypes conferring a decreased risk of Type 1 diabetes. ICA were detected in $2.7 \%(42 / 1584 ; 95 \%$ confidence interval $1.9-3.6 \%)$, IAA in $1.1 \%(17 / 1584 ; 0.6-1.7 \%)$, GADA in $1.3 \%$ $(21 / 1584 ; 0.8-2 \%)$ and IA-2A in $0.6 \%(10 / 1584$; $0.3-1.2 \%)$ of the sibs. There were no sex differences in the distribution of the $H L A-D Q B 1$ genotypes. There were neither any differences in the frequencies or titres of the various antibodies between the sexes. When the sibs were divided into two age groups
( $<5$ and $\geq 5$ years), $2.0 \%(15 / 734)$ of the younger subjects and $3.2 \%(27 / 850 ; p=0.16)$ of the older subjects tested positive for ICA. No differences were observed in the frequencies or titres of other antibodies between these two age groups.

The frequency of antibody positivity in the sibs was related to the genetic risk, those with genotypes conferring increased genetic risk being positive for various antibodies more often than those with decreased genetic risk (Table 1). No difference was seen in the frequency of ICA between male $(4 / 90 ; 4.4 \%)$ and female sibs $(7 / 81 ; 8.6 \%, p=0.42)$ among those with the high risk genotype. The number of positive children was too low for such a comparison in relation to the other autoantibody specificities. ICA-positive subjects with the high-risk genotype were on an average 2 years younger than those carrying the other genotypes $(p=0.04)$, while no such age difference could be seen when comparing sibs positive for IAA, GADA or IA-2A carrying the high-risk genotype with

Table 1. Frequency of ICA, IAA, GADA and IA-2A in children with $H L A D Q B 1$ genotypes conferring differential degrees of genetic risk to Type 1 diabetes

\begin{tabular}{|c|c|c|c|c|c|}
\hline$n$ & $\begin{array}{l}\text { I High risk } \\
171\end{array}$ & $\begin{array}{l}\text { II Moderate risk } \\
516\end{array}$ & $\begin{array}{l}\text { III Low risk } \\
422\end{array}$ & $\begin{array}{l}\text { IV Decreased risk } \\
475\end{array}$ & Statistics \\
\hline ICA & $\begin{array}{l}11(6.4) ; \\
3.3-11.2\end{array}$ & $\begin{array}{r}18(3.5) \\
2.1-5.5\end{array}$ & $\begin{array}{l}7(1.7) \\
0.7-3.4\end{array}$ & $\begin{array}{l}6(1.3) \\
0.5-2.7\end{array}$ & $\begin{array}{l}\chi^{2}=16.03 ; p=0.001 \\
\text { I vs III } p=0.005 \\
\text { I vs IV } p=0.001 \\
\text { II vs IV } p=0.04\end{array}$ \\
\hline IAA & $\begin{array}{l}4(2.3) \\
0.6-5.9\end{array}$ & $\begin{array}{l}9(1.7) \\
0.8-3.3\end{array}$ & $\begin{array}{l}1(0.2) \\
0.01-1.3\end{array}$ & $\begin{array}{l}3(0.6) \\
0.1-1.8\end{array}$ & $\begin{array}{l}\chi^{2}=8.42 ; p=0.04 \\
\text { I vs III } p<0.05 \\
\text { II vs III } p<0.05\end{array}$ \\
\hline GADA & $\begin{array}{l}5(2.9) ; \\
1.0-6.7\end{array}$ & $\begin{array}{r}13(2.5) \\
1.4-4.3\end{array}$ & $\begin{array}{l}2(0.5) \\
0.1-1.7\end{array}$ & $\begin{array}{l}1(0.2) \\
0.01-1.2\end{array}$ & $\begin{array}{l}\chi^{2}=15.82 ; p<0.001 \\
\text { I vs III } p=0.02 \\
\text { I vs IV } p=0.005 \\
\text { II vs III } p=0.02 \\
\text { II vs IV } p=0.002\end{array}$ \\
\hline IA-2A & $\begin{array}{l}3(1.8) \\
0.4-5.0\end{array}$ & $\begin{array}{l}6(1.2) ; \\
0.4-2.5\end{array}$ & $\begin{array}{l}1(0.2) \\
0.01-1.3\end{array}$ & $\begin{array}{l}0(0) \\
0-0.8\end{array}$ & $\begin{array}{l}\chi^{2}=9.83 ; p=0.02 \\
\text { I vs III } p=0.02 \\
\text { II vs IV } p=0.03\end{array}$ \\
\hline
\end{tabular}

Data are shown as absolute numbers, frequencies (\%) in brackets, and with $95 \%$ CI on the second line

Table 2. Levels of ICA, IAA, GADA and IA-2A in children with $H L A D Q B 1$ genotypes conferring differential degrees of genetic risk to Type 1 diabetes

\begin{tabular}{llllll}
\hline & I High risk & II Moderate risk & III Low risk & IV Decreased risk & Statistics \\
\hline ICA, JDF units & $18 ; 10-34$ & $12.5 ; 7.5-29.5$ & $10 ; 8-10$ & $8 ; 5.8-8.5$ & $\begin{array}{l}\chi^{2}=9.24 ; p=0.03 \\
\text { I vs III } p=0.03\end{array}$ \\
& & & & & I vs IV $p=0.03$ \\
& & & & & II vs IV $p=0.05$ \\
IAA, RU & $5.2 ; 2.5-13$ & $6.6 ; 2.2-22.5$ & $11.8^{\mathrm{a}}$ & $4.8 ; 2.6-6.6$ & $\chi^{2}=0.24 ; p=0.89$ \\
GADA, RU & $154.6 ; 91.4-181.3$ & $9.3 ; 7.5-23.6$ & $10^{\mathrm{b}}$ & $181.8^{\mathrm{a}}$ & I vs II $p=0.01$ \\
IA-2A, RU & $10.8 ; 8.7-79.4$ & $115 ; 87.1-128.3$ & $3.8^{\mathrm{a}}$ & & I vs II $P=0.04$ \\
\hline
\end{tabular}

${ }^{a}$ Only one positive subject

b Only two positive subjects
Only children positive for respective autoantibody were included in the analysis. Data are shown as medians; interquartile range 


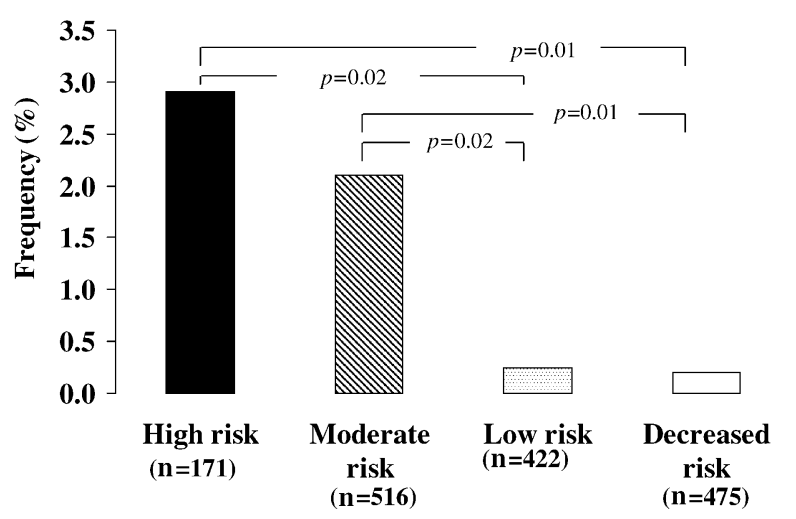

Fig. 1. Frequency of multiple autoantibodies $(\geq 2)$ in children with $H L A D Q B 1$ genotypes conferring differential degrees of genetic risk to Type 1 diabetes

the positive sibs having other genotypes. ICA titres among the ICA-positive sibs were clearly related to the $H L A$-conferred genetic risk, with the highest titres recorded in those with the high-risk genotype and the lowest values in those with genotypes conferring decreased risk (Table 2). GADA were also related to genetic risk, in that high-risk sibs had higher titres than moderate-risk sibs, whereas IA-2A titres were higher in the moderate-risk sibs than in the high-risk ones.

There were $302(19.1 \%)$ sibs in this cohort who carried the strongest protective HLA class II allele, $D Q B 1 * 0602$, and none of them tested positive for IAA or IA-2A, whereas $17(1.3 \%)$ of the other sibs had IAA $(p=0.04)$ and $10(0.8 \%)$ IA-2A $(p=0.12)$. The sibs with the $D Q B 1 * 0602$ allele also tended to have ICA and GADA less often than the other sibs [4 $(1.3 \%)$ vs $38(3 \%) ; p=0.11$, and $1(0.3 \%)$ vs 20 $(1.6 \%) ; p=0.09]$. None of the sibs with the $D Q B 1 * 0602$ allele had multiple autoantibodies $(\geq 2)$. There were no differences in the ICA or GADA titres between the sibs with the $D Q B 1 * 0602$ allele and any of the remaining groups of sibs (data not shown).

The frequency of multiple antibodies was also related to the degree of genetic risk. Of the high-risk sibs $2.9 \%$ (5/171) tested positive for multiple antibodies (Fig. 1), and at least three antibodies could be detected in three high-risk sibs (1.8\%) and six moderaterisk sibs $(1.2 \%)$ but in none of those with genotypes conferring low or decreased risk $\left(\chi^{2}\right.$ for trends $=$ $12.61 ; p=0.01)$. Among those with the high-risk genotype one sibling $(0.6 \%)$ and two among those with the moderate-risk genotypes $(0.4 \%)$ tested positive for all four antibodies $(p=1.00)$. There was also an apparent relation between the number of detectable antibodies and the ICA titres. Children with four antibodies had higher ICA titres (median $66 \mathrm{JDF} \mathrm{U}$, interquartile range 34-258 JDF $U$ ) than those with two antibodies (16.5 JDF U, 8-34 JDF U; $p=0.04$ ), or with ICA only (8 JDF U, 6-10 JDF U; $p<0.01$ ). The ICA titre was also higher in those with three antibodies (23 JDF U, 13.8-55 JDF U) than in those with one antibody $(p<0.01)$ and higher in those with two antibodies than in those with only one $(p=0.05)$.

A higher proportion of the 38 sibs with at least one first-degree relative affected by Type 1 diabetes tested positive for IA-2A $(2 ; 5.3 \%$ vs $8 ; 0.6 \% p=0.02)$ and multiple antibodies $(3 ; 7.9 \%$ vs $15 ; 1.0 \% ; p=0.008)$ than the sibs without affected family members.

\section{Discussion}

Population-wide screening of newborn infants for genetic risk of Type 1 diabetes is feasible and widely accepted in Finland. Close to 95\% of the parents of eligible newborn infants have given their consents to genetic screening in the DIPP study, and about $80 \%$ of the families with an at-risk baby have given written informed consent for autoantibody follow-up and have attended at least one follow-up visit [19]. Therefore the index cases of the DIPP study represent the general population, and the subjects of this work are derived from that population. The proportion of children with an increased genetic risk, i.e. with high or moderate-risk genotypes, is considerably greater among the sibs than among the index cases in the DIPP study, $43.4 \%$ as compared with $13.0 \%$ among the index cases. Of the 28615 index cases genotyped by June 1999, 3\% ( $n=862)$ had the high-risk genotype, $10 \%$ (2865) moderate-risk genotypes, $24.2 \%$ (6927) lowrisk genotypes and 62.8\% (17 961) genotypes conferring a decreased risk. This shows that the risk genotypes are enriched in this series relative to an unselected general cohort, due to the fact that these children are sibs of individuals who carry high or moderate risk genotypes. This adds to the power of the study, since the proportion of cases with enhanced genetic disease susceptibility is tripled relative to a completely unselected cohort.

Our results show that ICA were the most frequent autoantibodies detected in the sibs. This observation has, however, to be considered with caution, since differences in autoantibody frequency could reflect the cut-off thresholds used. Values of IAA, GADA and IA-2A positivity have been related to a healthy control population, while that has not been done with ICA. We aimed to find out whether there was any relation between the number of antibodies and the titre of ICA in those who tested positive for ICA, since both are measures of the aggressiveness of beta-cell autoimmunity and increase as the intensity of the beta-cell immunity increases. The results confirmed this association, as the ICA titres acted in concert with the number of antibodies: the higher the number of antibodies, the higher the ICA titre.

There was neither male nor female dominance in the frequency and titres of the four antibodies, and the sibs under 5 years of age (the youngest being 1.2 years) and those aged 5 years or older (the oldest be- 
ing 24.1 years) showed no differences in the frequencies of the various antibodies. This implies that the majority of such sibs seroconvert to antibody positivity under the age of 5 years. It has also been reported elsewhere that beta-cell autoimmunity both in offspring of parents with Type 1 diabetes [27] and in the general population [28] could be initiated early in life. The antibody titres were also of the same magnitude in the younger and older age groups, possibly suggesting that the titres after seroconversion remain relatively stable for a reasonable time, and that those who develop high titres of antibodies already have high titres at an early stage. An alternative explanation is that similar proportions of children have decreasing and rising antibody titres as they get older.

Our working hypothesis was that the prevalence of diabetes-associated antibodies is related to genetic disease susceptibility, being higher in those with an increased genetic risk. Our observations show that the $H L A D Q B 1$ genotype has an influence on the frequency of the four antibodies, this being most clearly seen for ICA and GADA, although those with increased risk genotypes also had higher frequencies of IA-2A and IAA than those with low or decreased risk genotypes. In addition, it could be seen that the ICA, GADA and IA-2A titres were dependent on the genetic risk, whereas IAA values did not differ between the risk groups. Sibs with high-risk and moderate-risk genotypes developed higher ICA titres than those carrying low or decreased risk genotypes. GADA titres were higher in the high-risk group than in the moderate-risk group, while the sibs with the moderate-risk genotypes had higher IA-2A titres than those with the high-risk genotype.

ICA-positive children in the high-risk group were younger than those in other risk groups. This implies that sibs with the high-risk genotype tend to seroconvert to ICA positivity at a younger age. This indicates that the $D Q B 1 * 02 / 0302$ genotype predisposes its carriers to an early appearance of ICA. ICA are the best characterised indicator of on-going beta-cell damage, and their predictive value has been observed to be high in first-degree relatives of children with diabetes $[29,30]$. There are indications that the beta-cell damage is faster and more aggressive in younger children than in older children [31], and the risk of developing clinical diabetes is higher for young ICA-positive sibs than for older ones [32].

Only sibs with high-risk and moderate-risk genotypes had more than two antibodies in this study. One child in the low-risk group had two antibodies (ICA and IA-2A), and one with genotypes conferring a decreased risk had two antibodies (IAA and GADA). This indicates either that the high- and moderate-risk genotypes predispose carriers to the emergence of antibodies linked with Type 1 diabetes or that low and decreased-risk genotypes protect them from such betacell autoimmunity. Our findings show that the HLA
$D Q B 1 * 0602$ allele protects subjects from the appearance of multiple antibodies, but it still points to a few individuals with this protective allele who test positive for single antibodies.

The number of children who had a family member affected by Type 1 diabetes was small $(n=38)$ resulting accordingly in a limited power in detecting differences in the frequency of various autoantibodies in relation to those with a negative family history for Type 1 diabetes. Nevertheless, the subjects with at least one affected family member were observed to have both IA-2A and multiple autoantibodies more frequently than the vast majority with no affected first-degree relatives.

In conclusion, it is shown here that the inherited susceptibility to Type 1 diabetes as defined in terms of HLA genes has a considerable influence on both the quality and quantity of signs of beta-cell autoimmunity in non-diabetic children derived from the general population.

Acknowledgements. This work was supported by the Medical Research Funds of Tampere, Oulu and Turku University Hospitals, the Medical Research Council of the Academy of Finland, the Juvenile Diabetes Research Foundation International (grants 197032 and 4-1998-274), the Novo Nordisk Foundation and EU Biomed 2 (BMH4-CT98-3314). We thank P. Arvilommi, R. Hakala, H. Savolainen, A.-M. Hämäläinen, S. Hoppu, A. Toivonen, M. Törmä, B. Nurmi, K. Rasimus, H. Pohjola, A. Stenius, K. Riikonen, U. Markkanen, P. Asunta, E. Koivistoinen, A. Suutari, R. Sihvo, and E. Mäntymäki for dedicating their time to the study. We are also grateful to S. Anttila, S. Heikkilä, M. Karlsson, P. Koramo, T. Mehtälä, S. Pohjola, R. Päkkilä, T. Lauren, R. Suominen, and J. Hakalax for their skilful technical assistance.

\section{References}

1. Menon RK, Sperling MA (1988) Childhood diabetes. Med Clin North Am 72: 1565-1576

2. Bingley PJ, Gale EAM (1989) Rising incidence of IDDM in Europe. Diabetes Care 12: 289-295

3. Karvonen M, Tuomilehto J, Libman I, LaPorte R (1993) A review of the recent epidemiological data on the worldwide incidence of Type I (insulin-dependent) diabetes mellitus. Diabetologia 36: 883-892

4. Diabetes Epidemiology Research International Group (1988) Geographic patterns of childhood insulin-dependent diabetes mellitus. Diabetes 37: 1113-1119

5. Reunanen A, Åkerblom HK, Käär M-L (1982) Prevalence and ten-year (1970-1979) incidence of insulin-dependent diabetes mellitus in children and adolescents in Finland. Acta Paediatr Scand 71: 893-899

6. Christau B, Åkerblom HK, Joner G, Dahlqvist G, Ludvigsson J, Nerup J (1981) Incidence of childhood insulin-dependent diabetes mellitus in Denmark, Finland, Norway and Sweden. A workshop report. Acta Endocrinol 98 [Suppl 245]: 68-80

7. LaPorte RE, Tajima N, Åkerblom HK et al. (1985) Geographic differences in the risk of insulin-dependent diabetes mellitus: the importance of registries. Diabetes Care 8 [Suppl 1]: 101-107 
8. Rewers M, LaPorte RE, King H, Tuomilehto J (on behalf of the DERI Study Group) (1988) Trends in the prevalence and incidence of diabetes: insulin-dependent diabetes mellitus in childhood. World Health Stat Q 41: 179-189

9. Thai AC, Eisenbarth GS (1993) Natural history of IDDM. Diabetes Rev 1: 1-14

10. Knip M (1997) Disease-associated autoimmunity and prevention of insulin-dependent diabetes mellitus. Ann Med 29: 447-451

11. Bertrams J, Baur MP (1984) Insulin-dependent diabetes mellitus. In: Albert ED, Baur MP, Mayr WR (eds) Histocompability testing. Springer, Berlin Heidelberg New York, pp 348-358

12. Davies J, Kawaguchi Y, Bennett ST et al. (1994) A genome wide search for human Type I diabetes susceptibility genes. Nature 371: 130-136

13. Rotter JI, Landaw EM (1984) Measuring the genetic contribution of a single locus to a multilocus disease. Clin Genet 26: 529-542

14. Pugliese A, Gianani R, Moromisato R et al. (1995) HLADQB $1 * 0602$ is associated with dominant protection from diabetes even among islet cell antibody-positive first-degree relatives of patients with IDDM. Diabetes 44: 608-613

15. Kulmala P, Savola K, Petersen J et al. (1998) Prediction of insulin-dependent diabetes mellitus in sibs of children with diabetes: a population-based study. J Clin Invest 101: 327-336

16. Bingley PJ, Christie MR, Bonifacio E et al. (1994) Combined analysis of autoantibodies improves prediction of IDDM in islet cell antibody-positive relatives. Diabetes 43: 1304-1310

17. Verge CF, Gianini R, Kawasaki E et al. (1996) Prediction of Type I diabetes in first-degree relatives using a combination of insulin, GAD and ICA512bdc/IA-2 antibodies. Diabetes 45: 926-933

18. Baisch JM, Weeks T, Giles R, Hoover M, Stastny P, Capra JD (1990) Analysis of HLA-D genotypes and susceptibility in insulin-dependent diabetes mellitus. N Engl J Med 322: 1836-1841

19. Kupila A, Muona P, Simell T et al. (2001) Feasibility of genetic and immunological prediction of Type I diabetes in a population-based cohort. Diabetologia 44: 290-297

20. Sjöroos M, Iitiä A, Ilonen J, Reijonen H, Lövgren T (1995) Triple-label hybridization assay for Type I diabetes-related HLA alleles. Biotechniques 18: 870-877
21. Ilonen J, Reijonen H, Herva E et al. (1996) Rapid HLADQB1 genotyping for four alleles in the assessment of IDDM risk in the Finnish population. Diabetes Care 19: 795-800

22. Bottazzo GF, Florin-Christensen A, Doniach D (1974) Islet-cell antibodies in diabetes mellitus with autoimmune polyendocrine deficiencies. Lancet ii: 1279-1282

23. Williams AJK, Bingley PJ, Bonifacio E, Palmer JP, Gale EAM (1997) A novel micro-assay for insulin autoantibodies. J Autoimmun 10: 473-478

24. Verge CF, Stenger D, Bonifacio E et al. (1998) Combined use of autoantibodies (IA-2 antibody, GAD antibody, insulin antibody, cytoplasmic islet cell antibodies) in Type I diabetes. Combinatorial islet autoantibody workshop. Diabetes 47: 1857-1866

25. Savola K, Sabbah E, Kulmala P, Vähäsalo P, Ilonen J, Knip M (1998) Autoantibodies associated with Type I diabetes mellitus persist after diagnosis in children. Diabetologia 41: 1293-1297

26. Savola K, Bonifacio E, Sabbah E et al. (1998) IA-2 antibodies - a sensitive marker of IDDM with clinical onset in childhood and adolescence. Diabetologia 41: 424-429

27. Ziegler AG, Hummel M, Schenker M, Bonifacio E (1999) Autoantibody appearance and risk for development of childhood diabetes in offspring of parents with Type I diabetes. Diabetes 48: 460-468

28. Kimpimäki T, Kupila A, Hämäläinen A-M et al. (2001) The first signs of $\beta$-cell autoimmunity appear in infancy in genetically susceptible children from the general population: The Finnish Type 1 Diabetes Prediction and Prevention Study. J Clin Endocrinol Metab 86: 8782-8788

29. Karjalainen J (1990) Islet cell antibodies as predictive markers for IDDM in children with high background incidence of disease. Diabetes 39: 1144-1150

30. Karjalainen J, Vähäsalo P, Knip M et al. (1996) Islet cell autoimmunity and progression to insulin-dependent diabetes mellitus in genetically high- and low-risk sibs of children. Eur J Clin Invest 26: 640-649

31. Karjalainen J, Salmela P, Ilonen J, Surcel HM, Knip M (1989) A comparison of childhood and adult Type I diabetes mellitus. N Engl J Med 320: 881-886

32. Thivolet C, Beaufree B, Geburher L, Chatelain P, Orgiazzi J (1991) Autoantibodies and genetic factors associated with the development of Type I (insulin-dependent) diabetes mellitus in first degree relatives of diabetic patients. Diabetologia 34: 186-191 